\title{
Reduced exercise capacity in persons with Down syndrome: cause, effect, and management
}

This article was published in the following Dove Press journal:

Therapeutics and Clinical Risk Management

7 December 2010

Number of times this article has been viewed

\author{
Goncalo V Mendonca' \\ Fernando D Pereira' \\ Bo Fernhall ${ }^{2}$ \\ 'Center of Human Performance \\ (CIPER), Faculty of Human Kinetics, \\ Technical University of Lisbon, Lisbon, \\ Portugal; ${ }^{2}$ Kinesiology and Community \\ Health, University of Illinois at Urbana \\ Champaign, Champaign, IL, USA
}

Correspondence: Goncalo V Mendonca Center of Human Performance (CIPER), Faculty of Human Kinetics,

Technical University of Lisbon,

Estrada da Costa, Cruz Quebrada, 1495-688 Cruz Quebrada Dafundo, Lisbon, Portugal

Tel +351933206691

Fax $+35|2| 4 \mid 49236$

Email gvmendonca@gmail.com
Abstract: Persons with Down syndrome (DS) have reduced peak and submaximal exercise capacity. Because ambulation is one predictor of survival among adults with DS, a review of the current knowledge of the causes, effects, and management of reduced exercise capacity in these individuals would be important. Available data suggest that reduced exercise capacity in persons with DS results from an interaction between low peak oxygen uptake $\left(\mathrm{VO}_{2 \text { peak }}\right)$ and poor exercise economy. Of several possible explanations, chronotropic incompetence has been shown to be the primary cause of low $\mathrm{VO}_{2 \text { peak }}$ in DS. In contrast, poor exercise economy is apparently dependent on disturbed gait kinetics and kinematics resulting from joint laxity and muscle hypotonia. Importantly, there is enough evidence to suggest that such low levels of physical fitness (reduced exercise capacity and muscle strength) limit the ability of adults with DS to perform functional tasks of daily living. Consequently, clinical management of reduced exercise capacity in DS seems important to ensure that these individuals remain productive and healthy throughout their lives. However, few prospective studies have examined the effects of structured exercise training in this population. Existent data suggest that exercise training is beneficial for improving exercise capacity and physiological function in persons with DS. This article reviews the current knowledge of the causes, effects, and management of reduced exercise capacity in DS. This review is limited to the acute and chronic responses to submaximal and peak exercise intensities because data on supramaximal exercise capacity of persons with DS have been shown to be unreliable.

Keywords: Down syndrome, peak exercise capacity, exercise economy, ventilatory threshold, exercise training

\section{Introduction}

Down syndrome (DS) is a chromosomal disorder occurring in about 1 per 650 to 1000 live births, and there is also a marked increase in prevalence with advanced maternal age. ${ }^{1-5}$ In Europe, DS accounts for $8 \%$ of all registered cases of congenital anomalies, and it is the most common cause of intellectual disability (ID)., 2,6,7

DS is characterized by altered psychomotor development and an increased risk of concomitant congenital defects and organic disorders, such as congenital heart and gastrointestinal defects, celiac disease, and hypothyroidism. ${ }^{8}$ Although life expectancy is still low, recently, there has been a substantial increase in life expectancy of persons with DS. Yang et al reported an average increase of 1.7 years of age at death per year studied from 1983 to $1997 .{ }^{9}$ This is mainly due to the successful surgical treatment of congenital heart disease and the improved treatment of congenital anomalies of the gastrointestinal tract. ${ }^{7,10,11}$ Average life expectancy of persons with DS has, therefore, 
increased into the late 50s and a person with DS who lived to the age of 83 years has been reported in the literature. ${ }^{12,13}$

Preventive health care has also contributed to improved overall outcome and quality of life in persons with DS. ${ }^{8}$ Furthermore, improved educational services and greater social acceptance of people with disabilities in the community have led to deinstitutionalization of people with DS. ${ }^{14}$ Given that ambulation is one important predictor of survival among adults with DS, this ever increasing number of community-dwelling individuals may well benefit from structured exercise interventions to remain productive and healthy throughout their lives. ${ }^{15}$ This notion becomes even more relevant when considering the ubiquitous nature of reduced exercise capacity in persons with DS. ${ }^{16-21}$ Accordingly, it is important to provide an etiological basis for such low levels of exercise capacity, as ultimately this will improve the clinical management of health-related physical fitness in persons with DS from childhood to adulthood. In addition, the effects of reduced exercise capacity on the ability of persons with DS to perform functional tasks (ie, tasks of daily living) needs investigation as this may be helpful in designing specific exercise interventions. Thus, the purpose of this article is to provide a comprehensive review of the current knowledge of the causes, effects, and management of reduced exercise capacity in DS. Because data on the supramaximal exercise capacity of persons with DS are scarce and unreliable, this review is limited to the acute and chronic responses to submaximal and peak exercise intensities in these individuals. ${ }^{22}$

\section{Causes for reduced exercise capacity in DS}

The most important physiological factors related to exercise capacity and work performance in humans include peak oxygen uptake $\left(\mathrm{VO}_{2 \text { peak }}\right)$, exercise economy, and the ventilatory threshold (VT). ${ }^{23,24}$ The finite rate of adjustment of oxidative phosphorylation to sudden increases and decreases in energy demand (ie, $\mathrm{VO}_{2}$ kinetics) is also important in minimizing the magnitude of the $\mathrm{O}_{2}$ deficit and debt, which can influence work performance. ${ }^{25}$ There is considerable evidence to support the clinical significance of all these factors as they are commonly altered in several pathological conditions (ie, coronary artery disease, myopathic heart disease, valvular heart disease, congenital heart disease, peripheral arterial disease, diabetes, anemia, obesity, obstructive lung disease, and restrictive lung disease).${ }^{26}$ Interestingly, healthy persons with DS (free from congenital or atherosclerotic heart disease, respiratory disease, or endocrine disorders) share common features with most of these pathological conditions, and this has been shown to limit their work performance during simple tasks, including treadmill exercise. ${ }^{19}$

\section{Peak oxygen uptake in persons with DS}

The upper limit of aerobic metabolism that can be maintained during exercise is termed $\mathrm{VO}_{2 \text { peak }} \cdot{ }^{27-30}$ This is usually achieved during exercise using relatively large muscle mass (ie, treadmill exercise) and represents the integrative ability of the heart to generate a high cardiac output, total body hemoglobin, high muscle blood flow, and muscle $\mathrm{O}_{2}$ extraction, and in some cases, the ability of the lungs to oxygenate the blood..$^{30-35}$

All previous studies on peak exercise capacity of individuals with DS have consistently found a lower $\mathrm{VO}_{2 \text { peak }}$, a shorter time to exhaustion, and a lower peak work rate in these individuals compared to age-matched controls. ${ }^{16-20,36,37}$ Fernhall et al first reported $\mathrm{VO}_{2 \text { peak }}$ values of $26 \mathrm{~mL} / \mathrm{kg} / \mathrm{min}$ for adolescents with DS and peak heart rates of $170 \mathrm{bpm} .{ }^{16,36}$ This is substantially different from the typical values attained by nondisabled adolescents during peak exercise testing $\left(\mathrm{VO}_{2 \text { peak }}:\right.$ 50-52 $\mathrm{mL} / \mathrm{kg} / \mathrm{min}$; heart rate: $\left.195-205 \mathrm{bpm}\right) .{ }^{38}$ Pitetti et al also obtained similar results in both their studies, showing that adults with DS exhibited $\mathrm{VO}_{2 \text { peak }}$ values from 22 to $24 \mathrm{~mL} / \mathrm{kg} / \mathrm{min}$ compared with $30-35 \mathrm{~mL} / \mathrm{kg} / \mathrm{min}$ for their peers without DS. ${ }^{17,37}$ The peak heart rates were also lower for the groups with DS (157-159 bpm) compared with those without DS (178-186 bpm). The reason for the low $\mathrm{VO}_{2 \text { peak }}$ and peak heart rates in DS was, at the time, difficult to ascertain, and some investigators believed that lack of motivation and, therefore, lack of valid peak effort could explain the findings. ${ }^{39,40}$ In contrast, others argued that DS might be associated with true chronotropic incompetence due to attenuated adrenergic responsiveness during exercise. ${ }^{16,41-43}$ According to this hypothesis, chronotropic incompetence would limit peak cardiac output and consequently produce a lower $\mathrm{VO}_{2 \text { peak }}$ in these individuals. Finally, it was also suggested that obesity, which is highly prevalent in persons with DS, could explain their reduced exercise capacity. ${ }^{41,44-47}$

With the purpose of exploring the 'lack of motivation' hypothesis, Fernhall et al tested the validity and reliability of treadmill peak exercise testing (graded exercise testing - GXT) in adolescents with DS. ${ }^{42}$ The authors used objective criteria to identify valid peak efforts such as a plateau in $\mathrm{VO}_{2}(<150 \mathrm{~mL} / \mathrm{min}$ increase $)$ with an increase in work rate or a plateau in heart rate ( $<2 \mathrm{bpm}$ increase) with increase in work rate concomitant with a respiratory exchange ratio $>1.0$. Results indicated that under these conditions 
(treadmill exercise testing and use of objective criteria for peak effort determination), peak exercise testing in persons with DS was as valid and reliable as in individuals without ID (reliability coefficient of 0.94 ). Consequently, these findings argued against the 'lack of motivation' hypothesis and suggested a true physiological limitation during acute exercise in persons with DS.

The 'chronotropic incompetence' hypothesis was subsequently explored in a study that compared the differences in cardiorespiratory capacity between adults with DS and those with other ID. ${ }^{18}$ The authors found that the lower peak heart rates of the subjects with DS explained their lower levels of aerobic capacity. Results were, therefore, in support of this hypothesis and further corroborated the notion that limited cardiac output at peak exercise is the likely explanation of the low work capacity in individuals with DS. This led to speculations of possible relationships between attenuated sympathetic response to exercise (ie, autonomic dysfunction), chronotropic incompetence, and low $\mathrm{VO}_{2 \text { peak }}$ in this population.

In another study, it was shown that peak heart rates in persons with DS were $\sim 30 \mathrm{bpm}$ lower than those predicted by the formula 220 minus age. ${ }^{48}$ However, a follow-up study by Guerra et al more decisively showed that individuals with DS likely exhibit true chronotropic incompetence during exercise. ${ }^{49}$ In this study, the chronotropic response index (CRI) of adults with DS was compared to that of nondisabled controls. The CRI is a submaximal exercise variable derived from the relative relation between heart rate and metabolic reserve. The CRI, in contrast to peak heart rate, is independent of effort, motivation, age, resting heart rate, and physical fitness. ${ }^{50,51}$ Not only did participants with DS show lower CRI values than controls, but they also exhibited values similar to those reported in nondisabled populations with true chronotropic incompetence (ie, coronary heart disease and heart failure $)(\mathrm{CRI}<0.9) .{ }^{50,52-54}$

The association between chronotropic incompetence and DS was subsequently confirmed by several reports showing significant differences between peak heart rates attained by these individuals and those of individuals without DS. ${ }^{20,21,55-62}$ Taken together, all these studies point toward strong evidence supporting the 'chronotropic incompetence' hypothesis as one of the primary causes for reduced $\mathrm{VO}_{2 \text { peak }}$ in persons with DS. The exact mechanism for this phenomenon is not completely understood, but there is strong evidence for blunted adrenergic responsiveness in persons with DS. ${ }^{43,57,58}$ This may also be related to altered autonomic function, as vagal withdrawal during exercise and spontaneous baroreceptor function have been shown to be reduced in individuals with DS. ${ }^{63-66}$ The most likely candidate is reduced catecholamine response to maximal exercise. ${ }^{43,58}$ Fernhall et al recently showed that individuals with DS exhibited only minor norepinephrine increases and no change in epinephrine in response to peak treadmill exercise occurred. ${ }^{58}$ Since the change in both epinephrine and norepinephrine was related to both peak heart rate and peak exercise capacity and it has been shown that changes in catecholamines are largely responsible for increases in heart rate at exercise intensities above the VT, it is highly likely that the reduced ability to produce catecholamines is the major cause of chronotropic incompetence in persons with DS. ${ }^{67}$

Arguments against the 'obesity' hypothesis first resulted from the work of Fernhall et al that found no significant relationships between reduced $\mathrm{VO}_{2 \text { peak }}$ and select anthropometric variables (body size and body mass). ${ }^{18}$ These findings thus suggested some degree of independence between peak exercise capacity and morphologic features typical of DS (lower height and increased body mass). Subsequently, it was shown that obesity was not related to the attenuated hemodynamic response of persons with DS during three autonomic provocative maneuvers (peak exercise, cold pressure test, and isometric handgrip). ${ }^{59}$ This was later confirmed by Figueroa et al who also found no association between impaired cardiac autonomic regulation during isometric handgrip and obesity in adults with DS. ${ }^{63}$ Furthermore, in contrast to individuals without DS, obesity has no effect on maximal heart rate and little effect on $\mathrm{VO}_{\text {2peak }}$ in persons with DS. ${ }^{68}$ Consequently, to the best of our knowledge, there is no scientific evidence supporting the 'obesity' hypothesis as a main cause of low $\mathrm{VO}_{\text {2peak }}$ in persons with DS.

Considering the dependency of $\mathrm{VO}_{2 \text { peak }}$ on ventilatory capacity, it seems possible that the reduced peak exercise capacity in DS corresponds to reductions in ventilatory function. In agreement, it has been reported that persons with DS typically exhibit low peak exercise minute ventilation. ${ }^{18,19,42,48}$ The lack of ability to achieve high rates of ventilation by individuals with DS could result from reduced airway size, small nasal passages, and large tongue, potentially making it more difficult to breathe during exercise. However, Fernhall and Pitetti reported that the ventilation of subjects with DS was found to be appropriate for their $\mathrm{VO}_{2}$ during peak exercise. ${ }^{19}$ This suggested that the reduced ventilation does not account for the low $\mathrm{VO}_{\text {2peak }}$ values in this population. Finally, it was also speculated that altered mitochondrial function in DS could impact muscle function during endurance exercise. ${ }^{20}$ This would be manifested by 
a delayed rate of $\mathrm{VO}_{2}$ increase in response to exercise and contribute to low $\mathrm{VO}_{2 \text { peak }}$ in individuals with DS. However, this is not supported by recent findings of preserved $\mathrm{VO}_{2}$ kinetics in adults with DS while responding to exercise. ${ }^{56}$

\section{VT in persons with DS}

The ability to exercise for long periods at high fractions of the $\mathrm{VO}_{\text {2peak }}$ is an important determinant of work performance. ${ }^{69-72}$ The self-selected fractional utilization of the $\mathrm{VO}_{2 \text { peak }}$ during endurance exercise is linked to the VT. ${ }^{29,73}$ Therefore, the VT is often used as a submaximal index of aerobic exercise capacity, and it has been described as the exercise intensity at which minute ventilation increases at a disproportional rate compared to the increase in $\mathrm{VO}_{2} \cdot{ }^{26,74,75}$ For clinical purposes, the VT has been used in a variety of populations because it does not necessitate peak exercise effort. ${ }^{76-80}$

The literature on the VT of persons with DS is very limited with only two previous studies available, making it very difficult to infer possible relationships between this physiological variable and poor exercise capacity in this population. ${ }^{55,56}$ The lack of research on this topic is probably related to the difficulty in detecting VT in most individuals with DS. Baynard et al showed that although detection rates approached $100 \%$ in adolescents with ID without DS, the VT was only detectable in $\sim 60 \%$ of those with DS. ${ }^{55}$ They also showed that the minute ventilation over time method yielded the best detection rate in adolescents with DS. Interestingly, it was found that the VT (expressed as a percentage of $\mathrm{VO}_{2 \text { peak }}$ ) of participants with DS did not differ from that of ID controls without DS (DS: 65\%-70\% vs controls with ID: $58 \%-61 \%$ ). Recent research conducted by Mendonca et al also found similar fractional utilization of $\mathrm{VO}_{2 \text { peak }}$ at the VT between adults with DS and nondisabled controls of similar age, sex, and body mass index (DS: 67.5\%; nondisabled controls: $63.3 \%) .{ }^{56}$ Several investigations agree that the VT occurs between $52 \%$ and $57 \%$ of $\mathrm{VO}_{2 \text { peak }}$ for nondisabled girls and boys aged between 11 and 20 years. ${ }^{80,81}$ Younger children aged 7-12 years exhibit higher relative VT, at $68 \%-75 \%$ of $\mathrm{VO}_{2 \text { peak }}{ }^{80}{ }^{8}$ For adults, the VT typically occurs at 50\%-70\% $\mathrm{VO}_{2 \text { peak }}$, although it can be as high as $80 \%-85 \% \mathrm{VO}_{2 \text { peak }}$ in highly trained individuals. ${ }^{69}$ Thus, persons with DS seem to have a relatively normal VT when expressed as a percentage of $\mathrm{VO}_{2 \text { peak }}$. Consequently, it is unlikely that their limited exercise capacity results from low VT. Nevertheless, this needs to be further investigated and actual measurements of blood lactate concentration during graded exercise would be valuable to help clarify this issue.

\section{Exercise economy in persons with DS}

Another important factor that contributes to endurance exercise capacity has been termed 'exercise economy'. ${ }^{24}$ Economy refers to how much speed or power can be generated for a given level of $\mathrm{VO}_{2}(\mathrm{~mL} / \mathrm{kg} / \mathrm{min})$ during activities such as walking, running, or cycling. Exercise economy reflects the interaction of numerous factors including muscle morphology, elastic elements, and joint mechanics in the efficient transfer of ATP to mechanical speed. Good exercise economy is manifested by lower fractional utilization of $\mathrm{VO}_{2 \text { eak }}$ at a given speed and, consequently, in a reduction in glycogen utilization and less reliance on $\mathrm{O}_{2}$-independent metabolism leading to attenuated metabolic acidosis. ${ }^{23}$ Even though $\mathrm{VO}_{\text {2peak }}$ is very important for high-level performances, the individual workload attained at peak exercise is a function of both $\mathrm{VO}_{\text {2peak }}$ and exercise economy. ${ }^{23}$ This led some authors to explore whether exercise economy of persons with DS further exacerbates the amount of physical work they can perform because of their low $\mathrm{VO}_{\text {2peak }}$. The main hypothesis was that due to several anatomical and functional characteristics of DS (ie, joint laxity, muscle hypotonia, and gait instability), these individuals would present lower walking economy than nondisabled controls during exercise. ${ }^{82,83}$

Although there are few studies on submaximal exercise capacity of persons with DS, recent research has provided important information on this issue. Mendonca et al first reported similar walking economy between adults with and without DS during horizontal treadmill exercise. ${ }^{62}$ However, in this study, the submaximal treadmill speed was selected on the basis of previous findings showing that adults with DS prefer very low walking speeds $(\sim 2.5 \mathrm{~km} / \mathrm{h})$. Because the $\mathrm{O}_{2}$ cost of locomotion $(\mathrm{mL} / \mathrm{kg} / \mathrm{km})$ displays a U-shape when analyzed as a function of walking speed, this might have placed the nondisabled participants at greater disadvantage compared to those with DS, thus limiting subsequent interpretations of the data. This suggested that the use of a wider range of walking speeds would be necessary to draw meaningful conclusions about walking economy in DS. While exploring this issue, Agiovlasitis et al showed an upward shift in the $\mathrm{U}$-shaped $\mathrm{O}_{2}$ cost of locomotion of adults with DS compared to that of nondisabled controls. ${ }^{84}$ Importantly, these results were obtained when comparing both groups at similar dimensionless Froude number walking speeds (dissipating the effects of shorter legs in participants with DS). Moreover, when expressing walking economy as a function of body mass $\left(\mathrm{VO}_{2} / \mathrm{kg}\right)$, it was also found that the $\mathrm{VO}_{2}$ increased more steeply with increases in 
walking speed in adults with DS than in controls. ${ }^{84}$ This was later confirmed by Mendonca et al. ${ }^{21}$ These authors further explored differences in the delta $\mathrm{VO}_{2}$ response to positive changes in walking grade between adults with and without DS. They found that increases in treadmill grade at constant speed yielded similar delta $\mathrm{VO}_{2}$ between groups, thus suggesting that individuals with DS responded as efficiently as nondisabled controls to increments in walking grade. Consequently, there is enough evidence in the literature to suggest that not only is the $\mathrm{VO}_{\text {2peak }}$ of persons with DS substantially reduced, these individuals also exhibit low exercise economy at speeds faster than their preferred walking speed, which further compromises their exercise capacity. Of several candidate biomechanical variables (kinematic and kinetic) possibly contributing to the lower walking economy in DS, dynamic balance has been shown to be particularly challenging to these individuals. ${ }^{84,85}$ Accordingly, this may well implicate higher metabolic cost at faster walking speeds. The use of higher levels of muscle stiffness and angular impulse (forcing) by persons with DS when walking on a treadmill may also contribute to higher energy expenditure during positive variations in walking speed. ${ }^{86}$

In summary, the existent research indicates that persons with DS show lower relative $\mathrm{VO}_{\text {2peak }}$ than controls without disabilities from childhood to adulthood. It is highly likely that this is due to reduced catecholamine response to dynamic exercise, which is manifested by chronotropic incompetence and limited cardiac output at peak exercise intensities. As reported by Baynard et al, this is different from that seen in individuals with ID without DS in whom the relative $\mathrm{VO}_{2 \text { peak }}$ is similar to that of nondisabled controls across all age groups. ${ }^{20}$ One possible contributor to the low peak aerobic capacity across all ages in persons with DS is reduced physical activity levels; however, there is compelling evidence to support a true physiological limitation to exercise performance in these individuals (ie, chronotropic incompetence). As importantly, adults with DS also show poor physiological response to submaximal exercise (ie, reduced exercise economy), and this further aggravates their limited exercise capacity. Because disturbances in dynamic balance during locomotion have been shown to occur in DS at a young age, it is possible that reduced exercise economy may also be manifested by children and adolescents with DS. ${ }^{82}$ Therefore, otherwise healthy persons with DS exhibit a clinical profile characterized by reduced exercise capacity at all ages. Among several possible causes, including limited exercise opportunities, there is enough evidence to support an altered physiological response to exercise performed at different intensity domains in this population.

\section{Effects of reduced exercise capacity in DS}

Neuromuscular strength and exercise capacity are important prerequisites for many activities of daily living, including tasks such as eating, dressing, rising from a chair, and walking. These factors are essential in maintaining independence and are important measures of functional ability. ${ }^{87}$ As mentioned, individuals with DS are significantly weaker and have lower $\mathrm{VO}_{\text {2peak }}$ than those with and without other forms of ID at all stages of life. ${ }^{20,88-91}$ Such findings suggest that compromised basic function may be one of the main effects of reduced exercise capacity in this population..$^{89,92-94}$ Exercise capacity is also related to vocational performance in adults with ID, and individuals removed from competitive employment show a decrease in adaptive skill functioning and quality of life. ${ }^{95-99}$

Even though it would seem reasonable to expect some association between low physical fitness (reduced exercise capacity and/or muscle weakness) and poor performance in tasks of daily living in persons with DS, only recently was this issue appropriately explored. Cowley et al analyzed relationships between three timed tasks of daily living (chair rise, gait speed, and stair ascent and descent), age, and physical fitness $\left(\mathrm{VO}_{2 \text { peak }}\right.$, knee extensor, and flexor strength). ${ }^{87}$ Findings indicated that knee extensor strength was the most influential variable in predicting timed task performance, followed by $\mathrm{VO}_{2 \text { peak }}$. In contrast, age was not a significant predictor of timed task performance in this population. Interestingly, the fact that $\mathrm{VO}_{2 \text { peak }}$ predicted functional ability (chair rise and stair ascent) in a group of young adults with DS contrasts with findings in adults of similar age without DS. Such relationships have only been shown to exist in nondisabled adults aged 65 years and over. ${ }^{100,101}$ This led the authors to speculate that functional ability and independency of individuals with DS could be greatly affected if their trajectory of $\mathrm{VO}_{2 \text { peak }}$ decline with age would be similar or worse to that of people without DS. This was relevant because an increased rate of biological aging had been previously shown to occur in DS (approximately twofold compared to nondisabled subjects). ${ }^{102}$ However, Baynard et al showed that $\mathrm{VO}_{2 \text { peak }}$ does not decline in these individuals after the age of $16 .{ }^{20}$ Consequently, in contrast to that hypothesized by Cowley et al, the relationship between low $\mathrm{VO}_{2 \text { peak }}$ and poor functional ability may possibly span 
all developmental stages of persons with DS and, therefore, be independent of the aging process. Accordingly, such a relationship may be inherent to DS itself and may not be affected by or predisposed to premature aging. The lack of association between age and performance on functional tasks of daily living, as described by Cowley et al, further supports this contention. ${ }^{88}$ Although the exact reason for the lack of $\mathrm{VO}_{\text {2peak }}$ decline with age in DS is not known, it is feasible that if this population has such low physical activity levels starting at a young age, any further reduction in physical activity will not manifest itself in an age-associated reduction in $\mathrm{VO}_{2 \text { peak }}$. Another possibility is that they may just stay active enough to maintain enough functionality to meet the demands of daily living while avoiding substantial decrements in their $\mathrm{VO}_{2 \text { peak }}$ as they age. ${ }^{20}$ Therefore, functional ability, in part mediated by exercise capacity, may well limit long-term employment and independence in this population, resulting in decreased community integration, increased need for services and support, and decreased quality of life.

Although little empirical data support this notion, children with DS exhibit fewer episodes of high intensity physical activity compared to their nondisabled peers. ${ }^{103}$ Physical activity patterns may be influenced by the energy expenditure during a certain activity. Thus, reduced exercise economy over a wide range of walking speeds may possibly provide a partial explanation for the high levels of sedentary behavior reported in this population $(\sim 79 \%){ }^{21,84,104}$ Considering that under normal circumstances, physical activity accounts for between $15 \%$ and $30 \%$ of a person's total daily energy expenditure, this may also contribute to the high prevalence of overweight reported in DS (males: 45\%; females: $56 \%$ ). ${ }^{44105}$ To gain a more comprehensive understanding on this topic, future research that assesses the relationship between these variables in DS would prove invaluable. Restricted opportunities to participate in exercise programs taking place at a community setting may also provide partial explanation for these findings. ${ }^{92}$ Even though such programs have been shown to be effective to improve muscle function in persons with DS, there is limited research on this topic. ${ }^{106}$

\section{Management of reduced exercise capacity in DS}

It is important for persons with DS to maintain their functional status so that they can lead healthy and satisfying lives without being institutionalized, especially as they age. Exercise training interventions targeted at children with DS are of particular importance because early intervention may have greater effects over the life span. Nevertheless, to the best of our knowledge, few prospective studies have examined the effects of structured exercise training in persons with DS and their findings are somewhat contradictory. Millar et al observed increases in work capacity but no changes in the $\mathrm{VO}_{2 \text { peak }}$ of 14 adolescents with DS after a 10-week, 3 days/week, aerobic exercise program. ${ }^{107}$ These findings were subsequently confirmed by Varela et al after a 16-week rowing program performed 3 days/week. ${ }^{109}$ This led the authors to speculate that the capacity for improving aerobic functioning in DS might be limited. Nevertheless, both studies reported gains in exercise endurance after training; however, they were unable to provide a definite explanation for these findings. More recently, Tsimaras et al were the first to document a significant increase in the $\mathrm{VO}_{2 \text { peak }}$ of adults with DS after an aerobic training regimen consisting of 3 sessions/week for 12 weeks. ${ }^{110}$ Similar findings were also reported after 12 weeks of a combined exercise program in adults with DS and after 28 weeks of multiergometer aerobic conditioning. ${ }^{62,111,112}$ Given these latest reports, there is evidence that adults with DS respond positively to structured exercise training, particularly under regimens of combined aerobic and resistance training, and this is further supported by a meta-analysis by Dodd and Shields. ${ }^{112}$ It is difficult to determine why some studies found increases in $\mathrm{VO}_{2 \text { peak }}$ with training while others did not. Tsimaras et al suggest that it may be due to inadequate monitoring of intensity in the studies that failed to show increases in $\mathrm{VO}_{2 \text { peak }}{ }^{109}$ Most of the studies mention difficulties in motivating the subjects to keep exercising; none reported the success rates of maintaining the required exercise intensity.

There are only five trials that investigated whether persons with DS have the capacity to improve their levels of muscle strength in response to progressive resistance training. Three of these trials included progressive resistance training and two used a combined exercise program. ${ }^{62,106,110,113,114}$ Overall, findings indicate that programs prescribed for a frequency of 3 days/week improve the upper- and lower-limb muscle strength of persons with DS. ${ }^{110,113,114}$ In contrast, training regimens of lower frequency (2 days/week) are apparently associated with gains in muscle endurance. ${ }^{62,106}$ Even though this might seem important, none of these studies analyzed possible relationships between gains in muscle strength or endurance and increased $\mathrm{VO}_{2 \text { peak }}$ in persons with DS after training.

Considering that the limitations to exercise capacity in DS result not only from reduced $\mathrm{VO}_{2 \text { peak }}$, but also from compromised exercise economy, there are still some relevant 
and unanswered questions about the potential benefits of exercise training in this population. While exploring these issues, Mendonca et al recently found significant improvements in walking economy (ranging from $6.6 \%$ to $10.4 \%$ ) after combined exercise training in adults with DS. ${ }^{62}$ Interestingly, it was also shown that this improved walking economy explained the gains seen in the work capacity (GXT time to exhaustion) of these individuals after training. Consequently, although not measured in their studies, the gains in work capacity reported by Millar et al and Varela et al were most likely due to improved exercise economy after training. ${ }^{107,108}$

Finally, until recently, it was not known whether the relative gains in physical fitness of people with DS paralleled those seen in nondisabled individuals. Mendonca et al showed that a group of adults with DS improved their physical fitness to a similar magnitude as adults without disabilities after 12 weeks of combined aerobic and resistance training. ${ }^{62}$ Overall, this represents an important practical implication for the management of reduced exercise capacity in persons with DS. Specifically, since adults with DS respond to combined exercise training as those without disabilities, this supports that conventional exercise prescription guidelines, as those recommended by the American College of Sports Medicine, are well suited for this population. ${ }^{115}$

\section{Conclusions}

Reduced exercise capacity in persons with DS represents a significant problem since low fitness and activity levels have been associated with reduced survival rates in this population. ${ }^{15}$ Although several other factors may also be implicated, physiological differences such as chronotropic incompetence and low levels of muscle strength and muscle hypotonicity are known to contribute to the problem. Fernhall et al suggested that the inability to reach expected maximal heart rates limits cardiac output of individuals with DS and subsequently limits their $\mathrm{VO}_{\text {2peak }}{ }^{18}$ The reason for these low maximal heart rates is apparently related to a combination between reduced adrenergic responsiveness and blunted vagal withdrawal during exercise. ${ }^{58,63}$ Although low levels of muscle strength and hypotonicity have been associated to low $\mathrm{VO}_{2 \text { peak }}$, they may also be a plausible cause of reduced exercise economy in this population. In contrast, even though the literature on this topic is scarce, the VT of persons with DS does not seem to limit their ability to respond appropriately to endurance exercise.

Reduced levels of muscle strength and low $\mathrm{VO}_{\text {2peak }}$ have been shown to be determinants of poor performance in tasks of daily living in persons with DS. ${ }^{87}$ The relationship between these variables is not affected by the aging process in these individuals and, therefore, spans all stages of their development. As a consequence, exercise training interventions targeted at children with DS are of particular importance.

Finally, the effect of exercise training has been shown to be beneficial for improving exercise capacity and physiological function in persons with DS. ${ }^{62,109-112}$ The literature suggests that a combined aerobic and resistance exercise program may have a larger impact on physical fitness than aerobic exercise alone in people with DS. This is supported by improvements seen in both $\mathrm{VO}_{\text {2peak }}$ and exercise economy resulting from combined exercise regimens. ${ }^{62,110}$ However, although there is enough evidence to suggest that programs designed to improve exercise capacity can be beneficial for people with DS, it is not known whether gains in physical fitness can be retained by this population over time because no study included a follow-up phase. The effect that a participant's age, sex, or concurrent health problem might have on program outcomes or on person's ability to participate in these programs also remains largely unknown. There is also a need to determine implications for longer term exercise training regimens and to further explore the effectiveness of increased opportunities to participate in exercise programs taking place in a community setting starting at a young age. These issues need to be addressed in future studies.

\section{Disclosure}

The authors report no conflicts of interest in this work.

\section{References}

1. Parker SE, Mai CT, Canfield MA, et al. Updated national birth prevalence estimates for selected birth defects in the United States, 2004-2006. Birth Defects Res A Clin Mol Teratol. 2010; DOI: 10.1002/bdra.20735.

2. Dolk H, Loane M, Garne E, et al. Trends and geographic inequalities in the prevalence of Down syndrome in Europe, 1980-1999. Rev Epidemiol Sante Publique. 2005;53 Spec 2:2S87-2S95.

3. Canfield MA, Ramadhani TA, Yuskiv N, et al. Improved national prevalence estimates for 18 selected major birth defects - United States 1999-2001. MMWR Morb Mortal Wkly Rep. 2006;54(51): 1301-1305.

4. Irving C, Basu A, Richmond S, Burn J, Wren C. Twenty-year trends in the prevalence of survival in Down syndrome. Eur J Hum Genet. 2008; 16(11):1336-1340.

5. Morris J, Alberman E. Trends in Down's syndrome live births and antenatal diagnoses in England and Wales from 1989 to 2008: analysis of data from the National Down Syndrome Cytogenetic Register. BMJ. 2009;339:b3794. Doi: 10.1136/bmj.b3794.

6. De Walle H, Cornel M. Survival rates of children with Down syndrome in the northern Netherlands, 1981-1991. Tijdschr Kindergeneeskd. 1995; 63:40-44. 
7. Leonard S, Bower C, Petterson B, Leonard H. Survival of infants born with Down's syndrome, 1980-1996. Paediatr Perinat Epidemiol. 2000; 14(2):163-171.

8. Roizen NJ, Patterson D. Down's syndrome. Lancet. 2003; 361(9365):1281-1289.

9. Yang Q, Rasmussen SA, Friedman JM. Mortality associated with Down's syndrome in the USA from 1983 to 1997: a population-based study. Lancet. 2002;359(9311):1019-1025.

10. Day SM, Strauss DJ, Shavelle RM, Reynolds RJ. Mortality and causes of death in persons with Down syndrome in California. Dev Med Child Neurol. 2005;47(3):171-176.

11. Kortenhorst MS, Hazekamp MG, Rammeloo LA, Schoof PH, Ottenkamp J. Complete atrioventricular septal defect in children with Down's syndrome: good results of surgical correction at younger and younger ages. Ned Tijdschr Geneeskd. 2005;149(11): 589-593.

12. Glasson EJ, Sullivan SG, Hussain R, Petterson BA, Montgomery PD, Bittles AH. The changing survival profile of people with Down's syndrome: implications for genetic counselling. Clin Genet. 2002; 62(5):390-393.

13. Chicoine B, McGuire D. Longevity of a woman with Down syndrome: a case study. Ment Retard. 1997;35(6):477-479.

14. Brown R. Down syndrome: the changing scene. J Dev Disabil. 2006; 12 Suppl 1:XI-XVI.

15. Eyman RK, Call TL. Life expectancy of persons with Down syndrome. Am J Ment Retard. 1991;95(6):603-612.

16. Fernhall B, Tymeson G, Millar L, Burkett N. Cardiovascular fitness testing and fitness levels of adolescents and adults with mental retardation including Down syndrome. Educ Train Ment Retard. 1989; 24:133-138.

17. Pitetti KH, Climstein M, Campbell KD, Barrett PJ, Jackson JA. The cardiovascular capacities of adults with Down syndrome: a comparative study. Med Sci Sports Exerc. 1992;24(1):13-19.

18. Fernhall B, Pitetti KH, Rimmer JH, et al. Cardiorespiratory capacity of individuals with mental retardation including Down syndrome. Med Sci Sports Exerc. 1996;28(3):366-371.

19. Fernhall B, Pitetti K. Limitations to physical work in individuals with mental retardation. Clin Exerc Physiol. 2001;3:176-185.

20. Baynard T, Pitetti KH, Guerra M, Unnithan VB, Fernhall B. Age-related changes in aerobic capacity in individuals with mental retardation: a 20-yr review. Med Sci Sports Exerc. 2008;40(11):1984-1989.

21. Mendonca GV, Pereira FD, Morato PP, Fernhall B. Walking economy of adults with Down syndrome. Int J Sports Med. 2010;31(1): $10-15$.

22. Guerra M, Gine-Garriga M, Fernhall B. Reliability of Wingate testing in adolescents with Down syndrome. Pediatr Exerc Sci. 2009; 21(1):47-54.

23. Jones A. The physiology of the world record holder for the women's marathon. Int J Sports Sci Coach. 2006;11:101-116.

24. Joyner MJ, Coyle EF. Endurance exercise performance: the physiology of champions. J Physiol. 2008;586(1):35-44.

25. Delorey DS, Paterson DH, Kowalchuck JM. Effects of ageing on muscle $\mathrm{O}_{2}$ utilization and muscle oxygenation during the transition to moderate-intensity exercise. Appl Physiol Nutr Metab. 2007;32(6): $1251-1262$.

26. Wasserman K, Hansen J, Sue D, Stringer W, Whipp B. Principles of Exercise Testing and Interpretation - Including Pathophysiology and Clinical Applications. 4th ed. Philadelphia (PA): Lippincott Williams \& Wilkins; 2005.

27. Joyner MJ. Modeling: optimal marathon performance on the basis of physiological factors. $J$ Appl Physiol. 1991;70(2):683-687.

28. Joyner MJ. Physiologic limiting factors and distance running: influence of gender and age on record performances. Exerc Sport Sci Rev. 1993;21:103-133.

29. Coyle EF. Integration of the physiological factors determining endurance performance ability. Exerc Sport Sci Rev. 1995;23:25-63.
30. Basset DJ Jr, Howley ET. Limiting factors for maximum oxygen uptake and determinants of endurance performance. Med Sci Sports Exerc. 2000;32(1):70-84.

31. Mitchell J, Sproule B, Chapman C. The physiological meaning of the maximum oxygen intake test. $J$ Clin Invest. 1958;37(4): $538-547$.

32. Kanstrup IL, Eckbloom B. Blood volume and hemoglobin concentration as determinants of maximal aerobic power. Med Sci Sports Exerc. 1984;16(3):256-262.

33. Rowel LB. Human Circulation: Regulation During Physical Stress. New York: Oxford University Press; 1986.

34. Dempsey JA. J.B. Wolffe memorial lecture. Is the lung built for exercise? Med Sci Sports Exerc. 1986;18(2):143-155.

35. Saltin B, Strange S. Maximal oxygen uptake: "old" and "new" arguments for a cardiovascular limitation. Med Sci Sports Exerc. 1992; 24(1):30-37.

36. Fernhall B, Tymeson G. Graded exercise testing of mentally retarded adults: a study of feasibility. Arch Phys Med Rehabil. 1987; 68(6):363-365.

37. Pitetti K, Fernandez J, Stafford J, Stubbs N. Evaluating the cardiovascular fitness of Down syndrome individuals. In: Aghazadeh F, editor. Trends in Ergonomics/Human Factors. North Holland, The Netherlands: Elsevier Science Publishers; 1988:941-947.

38. Roland T. The development of aerobic fitness in children. In: Armstrong N, Kirby B, Welsman J, editors. Children and Exercise XIX. Promoting Health and Well-being. 1st ed. London, UK: Chapman \& Hall; 1997:179-190.

39. Seidl C, Reid G, Montgomery DL. A critique of cardiovascular fitness testing with mentally retarded persons. Adapt Phys Activ Q. 1987; 4(2):106-116.

40. Lavay B, Reid G, Cressler-Chaviz M. Measuring the cardiovascular endurance of persons with mental retardation: a critical review. Exerc Sport Sci Rev. 1990;18:263-290.

41. Fernhall B. Physical fitness and exercise training of individuals with mental retardation. Med Sci Sports Exerc. 1993;25(4):442-450.

42. Fernhall B, Millar AL, Tymeson GT, Burkett LN. Maximal exercise testing of mentally retarded adolescents and adults: reliability study. Arch Phys Med Rehabil. 1990;71(13):1065-1068.

43. Eberhard Y, Eterradossi J, Therminarias A. Biochemical changes and catecholamine responses in Down's syndrome adolescents in relation to incremental maximal exercise. J Ment Defic Res. 1991; 35(Pt 2):140-146.

44. Rubin SS, Rimmer JH, Chicoine B, Braddock D, McGuire DE. Overweight prevalence in persons with Down syndrome. Ment Retard. 1998;36(3):175-181.

45. Fernhall B, Tymeson G. Validation of a cardiovascular fitness field test for adults with mental retardation. Adapt Phys Activ Q. 1988;5: 49-59.

46. Pitetti KH, Rimmer JH, Fernhall B. Physical fitness and adults with mental retardation. An overview of current research and future directions. Sports Med. 1993;16(1):23-56.

47. Pitetti KH, Tan DM. Cardiorespiratory responses of mentally retarded adults to air-brake ergometry and treadmill exercise. Arch Phys Med Rehabil. 1990;71(5):318-321.

48. Fernhall B, McCubbin JA, Pitetti KH, et al. Prediction of maximal heart rate in individuals with mental retardation. Med Sci Sports Exerc. 2001;33(10):1655-1660.

49. Guerra M, Llorens N, Fernhall B. Chronotropic incompetence in individuals with Down syndrome. Arch Phys Med Rehabil. 2003; 84(11):1604-1608

50. Lauer MS, Okin PM, Larson MG, Evans JC, Levy D. Impaired heart rate response to graded exercise. Prognostic implications of chronotropic incompetence in the Framingham Heart Study. Circulation. 1996;93(8):1520-1526.

51. Wilkoff BL, Miller RE. Exercise testing for chronotropic assessment. Cardiol Clin. 1992;10(4):705-717. 
52. Hinkle LE Jr, Carver ST, Plakun A. Slow heart rates and increased risk of cardiac death in middle-age men. Arch Intern Med. 1972; 129(5):732-748.

53. Ellestad MH, Wan MK. Predictive implications of stress testing. Follow-up of 2700 subjects after maximum treadmill stress testing. Circulation. 1975;51(2):363-369.

54. Keteyian SJ, Brawner CA, Schairer JR, et al. Effects of exercise training on chronotropic incompetence in patients with heart failure. Am Heart J. 1999;138(2 Pt 1):233-240.

55. Baynard T, Unnithan VB, Pitetti KH, Fernhall B. Determination of ventilatory threshold in adolescents with mental retardation with and without Down syndrome. Pediatr Exerc Sci. 2004;16(2):126-137.

56. Mendonca GV, Pereira FD, Fernhall B. Oxygen uptake kinetics during exercise in adults with Down syndrome. Eur J Appl Physiol. 2010; 110(3):575-583.

57. Bricout VA, Guinot M, Faure P, et al. Are hormonal responses to exercise in young men with Down's syndrome related to reduced endurance performance? J Neuroendocrinol. 2008;20(5): 558-565.

58. Fernhall B, Baynard T, Collier SR, et al. Catecholamine response to maximal exercise in persons with Down syndrome. Am J Cardiol. 2009;103(5):724-726.

59. Fernhall B, Otterstetter M. Attenuated responses to sympathoexcitation in individuals with Down syndrome. J Appl Physiol. 2003; 94(6):2158-2165.

60. Baynard T, Pitetti KH, Guerra M, Fernhall B. Heart rate variability at rest and during exercise in persons with Down syndrome. Arch Phys Med Rehabil. 2004;85(8):1285-1290.

61. Mendonca GV, Pereira FD, Fernhall B. Walking economy in male adults with Down syndrome. Eur J Appl Physiol. 2009;105(1):153-157.

62. Mendonca GV, Pereira FD, Fernhall B. Effects of combined aerobic and resistance exercise training in adults with and without Down syndrome. Arch Phys Med Rehabil. 2010; DOI: 10.1016/j.apmr.2010.09.015.

63. Figueroa A, Collier S, Baynard T, Giannopoulou I, Goulopoulou S, Fernhall B. Impaired vagal modulation of heart rate in individuals with Down syndrome. Clin Auton Res. 2005;15(1):45-50.

64. Heffernan KS, Baynard T, Goulopoulou S, et al. Baroreflex sensitivity during static exercise in individuals with Down syndrome. Med Sci Sports Exerc. 2005;37(12):2026-2031.

65. Iellamo F, Galante A, Legramante JM, et al. Altered autonomic cardiac regulation in individuals with Down syndrome. Am J Physiol Heart Circ Physiol. 2005;289(6):H2387-H2391.

66. Agiovlasitis S, Collier SR, Baynard T, et al. Autonomic response to upright tilt in people with and without Down syndrome. Res Dev Disabil. 2010;31(3):857-863.

67. Kjaer M. Adrenal medulla and exercise training. Eur J Appl Physiol Occup Physiol. 1998;77(3):195-199.

68. Fernhall B, Pitetti K, Guerra M. Impact of obesity and Down syndrome on maximal heart rate and work capacity in youth with mental retardation. Portuguese J Sport Sci. 2003;3:89-91.

69. Sjödin B, Svedenhag J. Applied physiology of marathon running. Sports Med. 1985;2(2):83-99.

70. Scrimgeour AG, Noaks TD, Adams B, Myburgh K. The influence of weekly training distance on fractional utilization of maximum aerobic capacity in marathon and ultramarathon runners. Eur J Appl Physiol Occup Physiol. 1986;55(2):202-209.

71. Costill DL, Thomason H, Roberts E. Fractional utilization of the aerobic capacity during distance running. Med Sci Sports Exerc. 1973; 5(4):248-252.

72. Maughan RJ, Leiper JB. Aerobic capacity and fractional utilisation of aerobic capacity in elite and non-elite male and female marathon runners. Eur J Appl Physiol Occup Physiol. 1983;52(1):80-87.

73. Jones AM, Carter $H$. The effect of endurance training on parameters of aerobic fitness. Sports Med. 2000;29(6):373-386.

74. Mahon A, Cheatham C. Ventilatory threshold in children: a review. Pediatr Exerc Sci. 2002;14:16-29.
75. McArdle WD, Katch FI, Katch VL. Exercise Physiology: Energy, Nutrition and Human Performance. 5th ed. Baltimore, MD: Lippincott Williams \& Wilkins; 2001.

76. Hebestreit H, Staschen B, Hebestreit A. Ventilatory threshold: a useful method to determine aerobic fitness in children? Med Sci Sports Exerc. 2000;32(11):1964-1969.

77. Ohuchi H, Nakajima T, Kawade M, Matsuda M, Kamiya T. Measurement and validity of the ventilatory threshold in patients with congenital heart disease. Pediatr Cardiol. 1996;17(1):7-14.

78. Reybrouck T, Eyskens B, Mertens L, Defoor J, Daenen W, Gewillig M. Cardiorespiratory exercise function after the arterial switch operation for transposition of the great arteries. Eur Heart J. 2001; 22(12):1052-1029.

79. Washington R, VanGundy J, Cohen C, Sondheimer H, Wolfe R. Normal aerobic and anaerobic exercise data for North American school-aged children. J Pediatr. 1988;112(2):223-233.

80. Climstein M, Pitetti KH, Barrett PJ, Campbell KD. The accuracy of predicting treadmill $\mathrm{VO}_{2 \max }$ for adults with mental retardation, with and without Down's syndrome, using ACSM gender- and activity-specific regression equations. J Intellect Disabil Res. 1993; 37(Pt 6):521-531.

81. Rhodes J, Geggel RL, Marx GR, Bevilacqua L, Dambach YB, Hijazi ZM. Excessive anaerobic metabolism during exercise after repair of aortic coarctation. J Pediatr. 1997;131(2):210-214.

82. Kubo M, Ulrich B. Coordination of pelvis-HAT (head, arms and trunk) in anterior-posterior and medio-lateral directions during treadmill gait in preadolescents with/without Down syndrome. Gait Posture. 2006; 23(4):512-518.

83. Smith BA, Ulrich BD. Early onset of stabilizing strategies for gait and obstacles: older adults with Down syndrome. Gait Posture. 2008; 28(3):448-455.

84. Agiovlasitis S, McCubbin JA, Yun J, Pavol MJ, Widrick JJ. Economy and preferred speed of walking in adults with and without Down syndrome. Adapt Phys Activ Q. 2009;26(2):118-130.

85. Black DP, Smith BA, Wu J, Ulrich BD. Uncontrolled manifold analysis of segmental angle variability during walking: preadolescents with and without Down syndrome. Exp Brain Res. 2007;183(4): 511-521.

86. Ulrich BD, Haehl V, Buzzi UH, Kubo M, Holt KG. Modeling dynamic resource utilization in populations with unique constraints: preadolescents with and without Down syndrome. Hum Mov Sci. 2004; 23(2):133-156.

87. Cowley P, Ploutz-Snyder L, Baynard T, et al. Physical fitness predicts functional tasks in individuals with Down syndrome. Med Sci Sports Exerc. 2010;42(2):388-393.

88. Croce RV, Pitetti KH, Horvat M, Miller J. Peak torque, average power, and hamstrings/quadriceps ratios in nondisabled adults and adults with mental retardation. Arch Phys Med Rehabil. 1996;77(4):369-372.

89. Pitetti KH, Boneh S. Cardiovascular fitness as related to leg strength in adults with mental retardation. Med Sci Sports Exerc. 1995; 27(3):423-428.

90. Angelopoulou N, Tsimaras V, Christoulas K, Kokaridas D, Mandroukas $\mathrm{K}$. Isokinetic knee muscle strength of individuals with mental retardation, a comparative study. Percept Mot Skills. 1999;88(3 Pt 1): 849-855.

91. Pitetti KH, Climstein M, Mays MJ, Barrett PJ. Isokinetic arm and leg strength of adults with Down syndrome: a comparative study. Arch Phys Med Rehabil. 1992;73(9):847-850.

92. Carmeli E, Ayalon M, Barchad S, Sheklow SL, Reiznick AZ. Isokinetic leg strength of institutionalized older adults with mental retardation with and without Down's syndrome. J Strength Cond Res. 2002; 16(2):316-320.

93. Carmeli E, Barchad S, Lenger R, Coleman R. Muscle power, locomotor performance and flexibility in aging mentally-retarded adults with and without Down's syndrome. J Musculoskelet Neuronal Interact. 2002;2(5):457-462. 
94. Carmeli E, Kessel S, Bar-Chad S, Merrick J. A comparison between older persons with Down syndrome and a control group: clinical characteristics, functional status and sensoriomotor function. Downs Syndr Res Pract. 2004;9(1):17-24.

95. Beasley CR. Effects of a jogging program on cardiovascular fitness and work performance of mentally retarded adults. Am J Ment Defic. 1982;86(6):609-613.

96. Croce R, Horvat M. Effects of reinforcement based exercise on fitness and work productivity in adults with mental retardation. Adapt Phys Activ Q. 1992;9(2):148-178.

97. Horvat M, Croce R. Physical rehabilitation of individuals with mental retardation; physical fitness and information processing. Crit Rev Phys Rehabil Med. 1995;7:233-252.

98. Kober R, Eggleton IR. The effect of different types of employment on quality of life. J Intellect Disabil Res. 2005;49(Pt 10): 756-760.

99. Stephens DL, Collins MD, Dooder RA. A longitudinal study of employment and skill acquisition among individuals with developmental disabilities. Res Dev Disabil. 2005;26(5): 469-486.

100. Alexander NB, Dengel DR, Olson RJ, Krajewski KM. Oxygenuptake $\left(\mathrm{VO}_{2}\right)$ kinetics and functional mobility performance in impaired older adults. J Gerontol A Biol Sci Med Sci. 2003;58(8): 734-739.

101. Arnett SW, Laity JH, Agrawal SK, Cress ME. Aerobic reserve and physical functional performance in older adults. Age Ageing. 2008; 37(4):384-389.

102. Nakamura E, Tanaka S. Biological ages of adult men and women with Down's syndrome and its changes with aging. Mech Ageing Dev. 1998; 105(1-2):89-103.

103. Whitt-Glover MC, O’Neill KL, Stettler N. Physical activity patterns in children with and without Down syndrome. Pediatr Rehabil. 2006; 9(2):158-164.

104. Stanish HI, Draheim CC. Walking habits of adults with mental retardation. Ment Retard. 2005;43(5):421-427.
105. Starling RD, Toth MJ, Carpenter WH, Matthews DE, Poehlman ET. Energy requirements and physical activity in free-living older women and men: a doubly labeled water study. J Appl Physiol. 1998; 85(3):1063-1069.

106. Shields N, Taylor NF, Dodd KJ. Effects of a community-based progressive resistance training program on muscle performance and physical function in adults with Down syndrome: a randomized controlled trial. Arch Phys Med Rehabil. 2008;89(7):1215-1220.

107. Millar AL, Fernhall B, Burkett LN. Effects of aerobic training in adolescents with Down syndrome. Med Sci Sports Exerc. 1993; 25(2):270-274.

108. Varela AM, Sardinha LB, Pitetti KH. Effects of an aerobic rowing training regimen in young adults with Down syndrome. Am J Ment Retard. 2001;106(2):135-144.

109. Tsimaras V, Giagazoglou P, Fotiadou E, Christoulas K, Angelopoulou N. Jog-walk training in cardiorespiratory fitness of adults with Down syndrome. Percept Mot Skills. 2003;96(3 Pt 2):1239-1251.

110. Rimmer JH, Heller T, Wang E, Valerio I. Improvements in physical fitness in adults with Down syndrome. Am J Ment Retard. 2004; 109(2):165-174.

111. Mendonca GV, Pereira FD. Influence of long-term exercise training on submaximal and peak aerobic capacity and locomotor economy in adult males with Down's syndrome. Med Sci Monit. 2009; 15(2):CR33-CR39.

112. Dodd KJ, Shields N. A systematic review of the outcomes of cardiovascular exercise programs for people with Down syndrome. Arch Phys Med Rehabil. 2005;86(10):2051-2058.

113. Davis W. Muscle stiffness in Down syndrome and other mentally handicapped subjects: a research note. J Mot Behav. 1987;19: 130-144.

114. Weber R, French R. Down's syndrome adolescents and strength training. Clin Kinesiol. 1988;42:13-21.

115. American College of Sports Medicine. ACSM's Guidelines for Exercise Testing and Prescription. 8th ed. Baltimore, MD: Lippincott Williams \& Wilkins; 2009.
Therapeutics and Clinical Risk Management

\section{Publish your work in this journal}

Therapeutics and Clinical Risk Management is an international, peerreviewed journal of clinical therapeutics and risk management, focusing on concise rapid reporting of clinical studies in all therapeutic areas, outcomes, safety, and programs for the effective, safe, and sustained use of medicines. This journal is indexed on PubMed Central, CAS,

\section{Dovepress}

EMBase, Scopus and the Elsevier Bibliographic databases. The manuscript management system is completely online and includes a very quick and fair peer-review system, which is all easy to use. Visit http://www.dovepress.com/testimonials.php to read real quotes from published authors. 